\title{
15 Calibrating the balance: The ethics of regulating the production and use of nanotechnology applications
}

\begin{abstract}
Nanotechnology (henceforth NT) is a rapidly advancing field with the potential of revolutionizing diverse areas such as electronics, health care, transport, and energy production. NT products and applications come with (potential) benefits and (potential) harms. The presence of potential harms calls for regulation. Both underregulation and overregulation - I argue - are morally undesirable. In the case of underregulation, stakeholders fall victim to the harmful effects of the technology. In the case of overregulation, stakeholders are deprived of the benefits of the technology. In this chapter, I identify the biases and factors that lead to underregulation and overregulation and offer solutions in response. More precisely, I argue that a lack of specific regulation, the presence of conflicts of interest and short-term economic incentives could lead to the underregulation of NT products and applications. Conversely, I argue that a negativity bias, harm aversion, the fear of opening "Pandora's box," and the intuition that what is natural is good and what is artificial (human-made) is bad could lead to overregulation. To avoid these pitfalls and the woes of underregulation and overregulation following in their wake, we need to set up a process - which I describe - in which policymakers and independent scientists closely collaborate.
\end{abstract}

Keywords: nanotechnology, underregulation, overregulation, conflicts of interest, economic incentives, negativity bias, harm aversion, laypeople intuitions

\subsection{Introduction}

Nanotechnology (henceforth NT) is a rapidly advancing field with the potential of revolutionizing diverse areas such as electronics, health care, transport, and energy production. An increasing number of nanoproducts (e.g., engineered cosmetics and food packaging) and NT applications(e.g., health-care applications for the diagnosis and treatment of diseases) find their way to the market. These products and technologies come with (potential) benefits and (potential) harms. The presence of potential harms

Acknowledgments: I want to thank my colleagues Dr. Stefaan Blancke and Dr. Alfred Archer for their insightful comments on a previous draft.

Michael Vlerick, Tilburg University, The Netherlands; University of Johannesburg, michaelvler ick@gmail.com,m.m.p.vlerick@uvt.nl 
calls for regulation. At present there is no comprehensive legal framework regulating the production, commercialization, and use of NT applications. There is - as Mnyusiwalla, Daar, and Singer [1] have argued - an important gap between ethical reflection on and regulation of NT products and applications on the one hand and the development, production, and use of these products and applications on the other hand. The gap has only widened since they published their paper in 2003.

This does not mean that we have to start developing regulation from scratch. As Ebbesen and colleagues [2] have pointed out, existing regulations in areas such as biotechnology and genetics provide a good basis for developing the regulatory framework for NT. Moreover, many of the moral considerations developed in these fields will also apply to NT. Nevertheless, we cannot merely apply existing regulations to NT products and applications. NT - like other technologies such as the genetic modification of crops(GMO's) and CRISPR gene editing - is a sui generis and potentially disruptive technology [3] with its own set of benefits and risks. This calls for the development of an equally sui generis regulation.

In this chapter, I want to contribute to this important task. I will analyze which biases and other factors lead to morally undesirable regulation and suggest ways to overcome these. In Section 15.2, I argue that both underregulation and overregulation of NT products and applications are undesirable. In the case of underregulation, stakeholders fall victim to the harmful effects of the technology. In the case of overregulation, stakeholders are deprived of the benefits of the technology. We should therefore "calibrate the balance" and strive for an optimal trade-off between (potential) benefits and (potential) harms. In Section 15.3, I identify elements that lead to underregulation and solutions to avoid this. In Section 15.4, I do the same for overregulation. In Section 15.5, I conclude.

\subsection{What kind of policy is morally desirable?}

\subsubsection{The problem with erring on the side of caution}

When confronted with a novel kind of technology that might cause harm, policymakersare often tempted to err on the side of caution. The influential "precautionary principle" incites policymakers to take precautionary measures if the potential harm for human health and the environment is substantial, even if it is uncertain that the harm would materialize in the absence of precautionary measures $[4,5]$. In this context, the EU has implemented a very stringent regulation for researching and producing GMO (genetically modified) crops to protect human health and the environment. Such a prudent approach - not willing to take any environmental or health risk - may seem morally desirable at first glance. After all, doesn't the policymaker have a moral duty to protect the environment and the health and well-being of all stakeholders? 
Erring on the side of caution, however, can be morally undesirable. It can lead to overregulation which denies society of the benefits of a technology [6]. We should not only consider the potential harm a technology can cause but also its (potential) benefits. Overregulation is not inherently preferable to underregulation.A human life lost because of precautionary measures barring the use of NT applications (e.g., applications to cure cancer) should not weigh less than a human life lost because of unwanted side effects of using NT applications. In this context, the overly restrictive European GMO regulation was recently - and I believe rightfully - criticized by leading scholars at European institutions. In an open letter, they argue that the current regulation robs European societies of the many benefits of GMO research and production. ${ }^{1}$

In a similar vein, given the many and substantial benefits of NT applications, the regulator should not deny us these benefits by playing it too safe. They should trade-off (potential) benefits and (potential) harms with the aim of providing "the greatest amount of good for the greatest number," as prominent "utilitarian" moral philosophers such as Jeremy Bentham [7] and John Stuart Mill [8] have argued. Defending such a utilitarian normative approach against rival approaches - such as Kantian deontology - is beyond the scope of this paper. However, I dare hope that many readers will agree with the moral imperative is to take into consideration both benefits and harms and strive for regulation that serves the interest of all of the stakeholders - human and non-human organisms, present and future generations - as well as possible.

\subsubsection{The difficulty of trading-off benefits and harms}

Trading-off (potential and established) benefits and harms of new technological applications is by no means an easy feat. Firstly, we do not know the extent of some of the benefits and harms and the probability that they will materialize. A NT cancer treatment, for example, might turn out to be more or less effective than expected. This uncertainty is especially relevant when it comes to harms. Many of the potential harms ascribed to nanoproducts (e.g., their negative impact on the environment and on human health) are not firmly established. They are risks that might or might not materialize. To make matters worse, there are not only the "known unknowns" but also the "unknown unknowns." NT applications might have totally unexpected benefits (e.g., entirely new areas in which they can be used than the ones for which they were developed) and cause completely unexpected harms.

Secondly, even the trade-off between known benefits and harms is not straightforward. Such benefits and harms are not always quantifiable. It might not be possible to

1 The initiative for the open letter came from the renowned Max Planck Institute for Developmental Biology and was signed by researchers from 117 research facilities. The letter can be retrieved from: https://www.mpg.de/13748566/position-paper-crispr.pdf - Last accessed on 19th of May 2020. 
quantify environmental and health-related benefits and harms. Moreover, even if these benefits and harms can be quantified (or if we can precisely estimate the extent of these benefits and harms), another major problem looms. When trading-off benefits and harms of a certain NT application, we are not only trading off benefits and harms on the same dimension. In many cases, we have to trade-off economic benefits and environmental costs (for example, if some useful applications could be "ecotoxic"); or we have to trade off health benefits (e.g., benefits provided by a NT cancer treatment) and social harms (such as increased inequality because the treatment is particularly expensive and only accessible to the wealthy). This trade-off along different dimensions is not specific to NT, but an inescapable part of most policy decisions.

Given that we are forced to compare apples and oranges (i.e., trade-off costs and benefits on different dimensions), given that we cannot quantify all harms and benefits (or even estimate their magnitude precisely), and given that we can never know (the full extent of) all harms and benefits, trading-off is not a matter of crunching the numbers. The policymaker must make value judgments. She must determine how much importance she accords to these different dimensions (i.e., to environmental integrity, human health, human wealth, social harmony, and so on) and trade-off the expected benefits and harms on these dimensions accordingly. Moreover, the policymaker must make decisions under uncertainty. Given the inherent uncertainty, policy decisions are particularly vulnerable to being biased. A number of biases and factors can lead to underregulation and overregulation, both of which are undesirable as pointed out above. The aim of this chapter is to identify these factors and biases and suggest ways to overcome them (or at least to keep them in check as much as possible).

\subsection{Underregulation}

\subsubsection{Major causes of underregulation}

The first cause of underregulation is a lack of specific regulation. This is our current predicament. There is no regulatory framework devoted to NT applications in place at the national or supra-national level. This is problematic, as I have pointed out in the introduction. Given the sui generischaracter of NT and the potentially major impact on health, environment, and economic development, the production and use of nanoproducts and NT applications should be regulated (over and above generic regulations - such as biotechnology or food and drug regulations - under which they now fall).The first step toward avoiding the harm that might arise because of underregulation is to develop specific regulation taking into accounts both the specific risks and benefits associated with NT. For this, we must overcome a "status quo bias" and the inertia that follows in its wake. 
A second possible cause of underregulation is conflict of interest. When the regulator has a vested economic interest in the commercialization of nanoproducts and NT applications, or is strongly influenced by people who do, she might be tempted to ignore some of the risks and harms in order to bring the product to the market. The same goes for the scientists informing the policymaker (see below on the importance of the involvement of scientists). If they are on the payroll of a company producing NT applications, there is an important conflict of interest and they might downplay the risks and harms. This is nothing new. Scientists employed by companies manufacturing harmful products have acted as "merchants of doubt" to prevent precautionary measures against smoking, pollution, and environmental degradation [9]. ${ }^{2}$

A third possible cause of underregulation is short-term economic incentive. When trading off economic benefits and environmental harms, nations might be tempted to tip the balance in favor of those economic benefits. The reason for that is that the economic benefits are reaped by the nation producing and exporting NT applications, while the environmental and health cost is often shared globally. Compare it with climate change. Nations have a short-term economic incentive to keep $\mathrm{CO}_{2}$ emission high since reducing $\mathrm{CO}_{2}$ emission requires investment in alternative technologies and/ or reducing industrial activities. The environmental cost of $\mathrm{CO}_{2}$ emission, however, is shared globally.

When benefits are reaped individually and costs are shared, we face a "tragedy of the commons" $[10,11]$. Imagine a pasture that can sustain a hundred sheep. It is used at full capacity by ten shepherds who each possess ten sheep. Any shepherd might nevertheless be tempted to add another sheep to his stock since this would mean a ten percent increase in wool revenue, while the cost of adding another sheep is marginal for the shepherd since it is shared by all shepherds (slightly less nutrition for all of the sheep). The fact that the shepherds have a short-term incentive to add more sheep (beyond the pasture's capacity) might ultimately lead to the demise of the pasture to the detriment of all shepherds. Similarly, a cost-benefit analysis in which individual nations trade off economic benefits and environmental costs might lead to the destruction of the common environmental good.

\subsubsection{Solutions}

In order to avoid underregulation we must first of all develop specific policy regulating the production and use of nanoproducts and NT applications. We must - as Mnyusiwalla and colleagues [1] put it - "close the gap" between regulation and

2 While conflicts of interest typically lead to underregulation, they might also distort policy in the opposite direction (leading to overregulation). For instance, the stringent European regulation banning meat that contains certain artificial beef growth hormones (which are deemed safe and approved in the US and Canada), might in part be attributable to protectionist economic policy. 
rapidly evolving technological innovation. In order to do so, it is of great importance that the policy is drafted by independent parties and informed by independent researchers to avoid conflicts of interest.Those policymakers should be free of undue influence or pressure exerted by lobbying parties (which could be the case, for instance, if they received financial support from industrial players with an economic interest in the products they are regulating).

A good democratic solution to avoid such conflicts of interests is to have a policy drafted by deliberative citizen councils. Such councils are composed of a representative sample of the population (often appointed by sortition). After being thoroughly informed by experts, they deliberate with the aim of reaching a high degree of consensus around certain policy proposals. Not only are the appointed citizens free from pressure by interest groups, they are also free to consider the long term (in contrast to elected politicians who might be reticent to impose measures which are costly in the short term for fear of losing the next elections). Moreover, social experiments with such citizen councils show that they often come up with thoughtful and sensible proposals [12-15].

Finally, to avoid a "tragedy of the commons," there should be multilateral - ideally global - agreement on and coordination of NT regulation. If nations draft and implement regulation independently, they might tip the balance in favor of their short-term economic interests at the detriment of the (shared) environment. Global coordination on policy, however, is by no means an easy feat. Think of the difficulty to reach a global agreement on climate policy [14, 15]. Supra-national and global institutions such as the United Nations (UN), the World Health Organization (WHO), and the World Trade Organization (WTO) - have a crucial role to play in facilitating such an agreement. While some global institutions are concerned with the ethical implications of NT and have made recommendations - the WHO drafted a document in 2012 on NT and human health reviewing the extant evidence of possible harms and advising a precautionary approach ${ }^{3}$ - this involvement should increase. If we leave policymaking to nations, we risk underregulationand the mass production of certain (potentially) harmful applications.

\subsection{Overregulation}

\subsubsection{Major causes of overregulation}

A number of important biasesand unfounded intuitionscan lead to overregulation. These biases explain why policymakers sometimes take overly precautionary measures

3 See: https://apps.who.int/iris/bitstream/handle/10665/108626/e96927.pdf;jsessionid= 5F33A5D5177F8C8EE2A78D1E938AA15A?sequence=1 - Last accessed on 19th of May 2020. 
when faced with new technologies (e.g., the GMO regulation of the EU) and why a rigid application of the precautionary principle - urging policymakers to eliminate risks at all costs (without considering the potential benefits - see [6, 16, p. 4], but also [17] for a reply) is so influential. A first important bias contributing to overregulation is the negativity bias. As Rozin and Royzman [18] explain, expected negative outcomes generally create a stronger affective response and therefore tend to weigh more on our decisions than expected positive outcomes. Rozin and Royzman [18, p. 298] refer to this as "negativity dominance." From an evolutionary perspective this makes sense, since paying attention (and remembering) threats generally increases an organism's chance of survival and reproduction more than paying attention to gains and benefits. This evolved bias explains why policymakers might accord too much weight to potential harms and costs and undervalue benefits when trading-off.

A second psychological feature that contributes to overregulation is harm aversion. Most humans are endowed with an aversion to harm others, especially if those others are considered in-group members. Cushman and colleagues [19] found that even "pretend" harmful acts, such as pointing a fake gun at somebody, causes strong physical reactions of aversion (namely increased peripheral vasoconstriction) (see also [20]).The moral aversion we feel for harmful acts is stronger than the aversion we feel for harmful omission (compare throwing somebody in a pond and causing that person to drown with refraining from saving a drowning person even if there's absolutely no personal risk or cost involved in doing so). Whether or not this intuition is justified - many moral philosophers have argued that - it is beyond the scope of this chapter.

Harm aversion leads policymakers to accord more weight to negative effects brought about by allowing the production of NT products or use of NT applications (which constitutes a harmful action) than by negative effects brought about by not allowing the production and use of such products and applications (which constitutes a harmful omission). Moreover, given that the public shares this intuition and that harmful actions are more conspicuous than harmful omissions, the former is typically (much) harder to justify to the public than latter (which often remains unspecified). Therefore, the prospect of people dying from nanoparticle intoxication, for example, is likely to be a stronger concern for policymakers than (the same number of) people dying because a medical NT application was not made available. This too leads to overregulation since it moves the policymakers to accord more importance to (potential) harms - which if ignored or underestimated would cause harmful actions - than to (potential) benefits - which if ignored or underestimated would cause harmful omission.

A third aspect that can lead to overregulation is the fear of "opening Pandora's box." The idea is that once we allow the development and production of disruptive technologies, there is no way back and we open the door to the many harms they might cause. As Davis and Macnaghton [21] point out, this is a prominent lay narrative. It captures the fear we have of unknown risks and harms. To a certain extent this fear is warranted. As indicated above, there are unknown risks, and the policymaker 
should be aware of this and proceed cautiously. However, she must also take the unknown benefits into account. The fact that we tend to focus on the unknown risks is a product of the first bias we discussed: our evolved negativity bias.

There is however an added dimension to the fear of opening Pandora's box. It also assumes that if we allow the production and distribution of some NT applications that are deemed safe, we irrevocably open the door for other NT applications that could be harmful. This however need not be the case. We can - and should regulate the production and use of NT applications on a case-by-case basis. Allowing one kind of application deemed safe, does not mean that other applications should be allowed without further consideration. Furthermore, while it is true that, given the presence of unknown risks, the policymaker might mistakenly allow the production of harmful NT applications, this does not mean that we cannot put these applications "back in the box." In fact, we frequently managed to put harmful technological innovations back in the box. We banned the use of toxic asbestos in building materials and CFC (chlorofluorocarbons) - which turned out to damage the ozone layer - in aerosols. There is no reason we would not be able to do so with NT applications that turn out to cause unexpected harm. ${ }^{4}$

A final unfounded but exceptionally tenacious bias which could lead to the overregulation of NT applications is the view that what is "natural is good and what is artificial (human-made) is bad." Nature, according to this view, should not be messed with. If we alter natural substances artificially (e.g., by altering matter at the nano-level) we invite all sorts of harms and hazards upon us. This widespread intuition (among laypeople) has turned the public opinion (and the European regulators) against GMO crops, despite the many scientific studies establishing that GMO crops are safe to consume [22]. While NT has not evoked a popular opposition of this magnitude (yet), the same fear of "messing with nature" applies and has been observed in lay narratives on NT [21]. This might lead to a backlash against NT and move policymakers to overregulate. A proper assessment of the risks of technological innovations (and a proper tradeoff between benefits and risks) should be based on evidence not on intuition.

\subsubsection{Solutions}

In order to prevent overregulationas a result of these psychological biases and unfounded intuitions, we must ensure that regulation is based on the best available

\footnotetext{
4 It is of course possible that the fear of opening Pandora's box is justified. An application could cause strong and irreversible harm if it is produced and distributed (even if it is banned shortly after). If this doom scenario is at all likely, this should of course tip the balance in favor of strong precautionary measures. Remember that the policymaker should not only consider known benefits and harms but also take into account the probability of unidentified benefits and harms materializing when she trades off benefits and harms.
} 
scientific evidence. This in turn requires close collaboration between policymakers and (independent) scientists. Scientific experts can provide the evidence and they are less likely to succumb to some of the unfounded intuitions (especially the view that what is natural is good and what is artificial is bad). We must also adhere to a formal process of decision-making.

Such a process would consist of four important steps. First, the (potential) benefits and (potential) harms must be identified. This should be done on a case-by-case basis, since different nanoproducts and NT applications come with different benefits and harms. Second, the positive and negative impacts on different dimensions such as human health, the environment, and economic development - must be estimated as precisely as possible (although quantifying these impacts will not always be possible, as mentioned above). Third, the policymakers must trade-off (possible) benefits and (possible) harms with the aim of producing the best possible outcome for all of the stakeholders. It is vital that they are aware of the biases (described above) that might distort their judgment and that they should attempt to eliminate these to the best of their ability. Fourth, after the policy has been implemented, its effects must be closely monitored. New insights are bound to arise once the products and applications are distributed and used. These new insights should then inform new measures (e.g., relaxing the regulation if it seems safe to do so or making the regulation more stringent if unexpected harms occur).

In order to make the best trade-off in the light of rapidly evolving scientific insights and new data, we should strive for a dynamic - not a static - regulation. Regulation should regularly be updated in the light of advancing knowledge. This should also alleviate worries of opening up Pandora's box. It is not because we allow the production and use of nanoproducts and NT applications based on current and flawed information that we cannot retract this in the future when unexpected harms turn up. Updating regulation regularly protects us against suffering from the woes of underregulation and overregulation for extended periods of time.

Throughout the entire process, the involvement of scientific experts is vital. The input of independent scientific experts is indispensable in every step of the process. It is obviously necessary to identify (possible) benefits and (possible) harms of a novel NT application (step 1), to estimate their impact on different dimensions (step 2) which requires the input of scientific experts in these different relevant fields - and to monitor the effects of the regulation to adapt it when necessary (step 4). But even in step 3, the actual drafting of the regulation by policymakers, the involvement of scientific experts is important.

This does not mean that the regulation should be drafted by scientists - this would amount to technocratic decision-making - only that the democratically appointed policymakers should be closely assisted and informed by scientific experts in all relevant fields (i.e., in all dimensions on which the applications might produce benefits and harms) while making their decisions. This is necessary in order to prevent 
that the policymakers from falling prey to some of the biases and unfounded intuitions discussed above.

Of course, this will not eradicate all biases from the process. Policymakers might decide to ignore the advice of scientists. Moreover, whereas scientists will be less likely to succumb to some of these biases and unfounded intuitions, they are not immune to biased reasoning. Nobody is. They might, for instance, ignore or underestimate some of the risks in their enthusiasm for the potential of NT applications, especially if they have contributed to developing the application. Conversely, some experts might play it too safe because of a negativity bias or because of harm aversion. Both policymakers and assisting scientific experts should therefore be (made) aware of the biases that might affect their judgment in order to eliminate them to the best of their ability.

\subsection{Conclusion}

NT is developing at a swift pace. This is good news. Technological innovation often leads to an increase in human well-being. It leads to longer lifespans, living in better conditions. NT is no different. It promises to contribute substantially to better, longer lives and to a better environment for present and future generations. However, the rapid scientific progress in NT also presents us with an important challenge. Given that nanoproducts and NT applications come with risks, their production, distribution, and use should be regulated.

The task that faces the regulator (and the scientists informing and assisting the regulator) is considerable. Not only must they regulate on a case-by-case basis given that the risk vs benefit profile of different applications can vary widely - they must also frequently revise regulation in the light of the latest findings (and the monitoring of the effects of the policy). In addition to being time-consuming, their task is a difficult one. Given the possibility of unknown benefits and harms materializing and the necessity to trade off benefits and harms on different dimensions, deciding on the optimal trade-off is no exact science. It is therefore especially vulnerable to biased reasoning.This is where the importance of a processand the involvement of experts come in. The purpose of such a process is to ensure a "calibrated balance" on which benefits and harms are weighed. Only with a properly calibrated balance (and the right scientific input) can we avoid the woes of under-regulation and overregulation.

\section{References}

[1] Mnyusiwalla A, Daar AS, Singer PA. Mind the gap: Science and ethics in nanotechnology. Nanotechnology 2003, 14, R9-R13.

[2] Ebbesen M, Andersen S, Besenbacher F. Bulletin of science. Technol Soc 2006, 26, 6, 451-62. 
[3] Lu L, Lin B, Liu J, Yu C. Ethics in nanotechnology: What's being done? What's missing? J Bus Ethics 2012, 109, 4, 583-98.

[4] Sandin P. Dimensions of the precautionary principle. Hum Ecol Risk Assess 1999, 5, 889-907.

[5] Sandin P. Common-Sense Precaution and Varieties of the Precautionary Principle. Lewens T Ed., Risk: Philosophical Perspectives. Routledge, 2007, 99-112.

[6] Sunstein C. Laws of Fear: Beyond the Precautionary Principle. Cambridge (UK), Cambridge University Press, 2005.

[7] Bentham J. An Introduction to the Principles of Morals and Legislation. New York, Prometheus Books, 1789.

[8] Mill JS. Crisp R ed. Utilitarianism. Oxford, Oxford University Press, 1863.

[9] Oreskes N, Conway E. Merchants of Doubt: How a Handful of Scientists Obscured the Truth on Issues from Tobacco Smoke to Global Warming. New York, Bloomsbury Press, 2010.

[10] Hardin G. The tragedy of the commons. Science 1968, 162, 1243-48.

[11] Vlerick M. The evolution of social contracts. J Soc Ontol 2020a, 5, 2, 181-203.

[12] Fishkin J. When the People Speak: Deliberative Democracy and Public Consultation. Oxford, Oxford University Press, 2009.

[13] Steiner J. The Foundations of Deliberative Democracy: Empirical Research and Normative Implications. Cambridge, MA, Cambridge University Press, 2012.

[14] Vlerick M (2019). De tweede vervreemding: Het tijdperk van de wereldwijde samenwerking. Tielt, Belgium, Lannoo.

[15] Vlerick M. Towards global cooperation: The case for a Deliberative Global Citizens' Assembly. Global Policy 2020b, 11, 3, 305-14.

[16] Bodansky D. Scientific uncertainty and the precautionary principle. Environment 1991, 33, 4-5, 43-44.

[17] Sandin P, Peterson M, Hansson S, Ruden C, Juthe A. Five charges against the precautionary principle. J Risk Res 2002, 5, 287-99.

[18] Rozin P, Royzman EB. Negativity bias, negativity dominance, and contagion. Pers Soc Psychol Rev 2001, 5, 4, 296-320.

[19] Cushman F, Gray K, Gaffey A, Mendes W. Simulating murder: The aversion of harmful action. Emotion 2012, 12, 1-7.

[20] Vlerick M. Better than Our Nature? Evolution and Moral Realism, Justification, and Progress. Ruse M, Richards R eds, Handbook of Evolutionary Ethics. Cambridge University Press, 2017, 226-39.

[21] Davies SR, Macnaghten P. Narratives of mastery and resistance: Lay ethics of nanotechnology. Nanoethics 2010, 4, 141-51.

[22] Blancke S, Van Breusegem F, De Jaeger G, Braeckman J, Van Montagu M. Fatal attraction: The intuitive appeal of GMO opposition. Trends Plant Sci 2015, 20, 7, 414-18. 
